\title{
Cellular expression of plasma prekallikrein in human tissues
}

\author{
Edwin Fink', Kanti D. Bhoola ${ }^{2,3}$, Celia Snyman³, \\ Peter Neth ${ }^{1}$ and Carlos D. Figueroa ${ }^{4, *}$ \\ ${ }^{1}$ Abteilung für Klinische Chemie und Klinische \\ Biochemie, Chirurgische Klinik Innenstadt, Ludwig- \\ Maximilians-Universität München, Nussbaumstr. 20, \\ D-80336 Munich, Germany \\ ${ }^{2}$ The Lung Institute of Western Australia and Centre for \\ Asthma, Allergy and Respiratory Research, University of \\ Western Australia, Hospital Avenue, Nedlands 6009, \\ Perth, WA, Australia \\ ${ }^{3}$ Durban Institute of Technology, Natal and ML Sultan \\ Technikons, Faculties of Health and Biological Sciences \\ and Microbiology, Durban 4001, South Africa \\ ${ }^{4}$ Instituto de Histologia y Patologia, Universidad Austral \\ de Chile, Casilla 567, Isla Teja, Valdivia, Chile \\ ${ }^{*}$ Corresponding author \\ e-mail: cfiguero@uach.cl
}

\begin{abstract}
Plasma prekallikrein (PPK) is synthesised in hepatocytes and secreted into the blood, where it participates in the surface-dependent activation of blood coagulation, fibrinolysis, kinin generation and inflammation. Recently we demonstrated by quantitative RT-PCR that the human PPK gene is transcribed not only in the liver, but also in various non-hepatic human tissues at significant levels. However, up to now no reliable information is available concerning protein synthesis in the corresponding human tissues. Here we demonstrate by immunohistochemical studies that PPK or plasma kallikrein (PK) is localised in cells of different embryologically derived human tissues. In the human nephron, single cells of the distal tubules stained intensely, while the cytoplasm of cells forming proximal tubules and collecting ducts stained uniformly. PPK/PK was localised in hepatic epithelial cells of the liver, in cells of the pancreatic islet of Langerhans, in the interstitial Leydig cells of the testes, in the follicular and thecal granulosa cells of the ovary, and in the parotid gland, oesophagus, skin, respiratory tract, prostate and breast. We conclude that the cellular localisation of PPK/PK in multiple different progenitorderived cells indicates specific cellular functions of this enzyme, in addition to its known function in the blood.
\end{abstract}

Keywords: cellular functions of plasma prekallikrein; kidney; KLKB1; pancreas; plasma kallikrein; plasma prekallikrein.

\section{Introduction}

Plasma and tissue kallikreins belong to the family of serine proteases to which several important physiological functions have been ascribed. Of these, the notable func- tions are modulation of cardiovascular dynamics, activation of complement and the initiation of inflammatory responses (Bhoola et al., 1992). The primary protease action of the two kallikreins is the formation of the vasoactive kinin peptides from endogenous multifunctional protein substrates termed kininogens.

The focus of this study is plasma prekallikrein (PPK), the zymogen of plasma kallikrein (PK), which is a singlechain glycoprotein that is synthesised in hepatocytes and secreted into the blood, where it forms a complex with its endogenous substrate, high-molecular-weight kininogen (Bhoola et al., 1992). PPK is encoded by a single gene $(K L K B 1)$ of approximately $31 \mathrm{~kb}$ in length that is located on chromosome $4 \mathrm{q} 34-35$ and is structurally similar to the thromboplastin antecedent factor (factor XI) gene (Asakai et al., 1987). The gene consists of 15 exons, the first two exons encoding the $5^{\prime}$-untranslated region and the signal peptide, the next eight the heavy chain, and the last five exons the light chain representing the protease segment of the molecule (accession no. AF232734-42).

Recent studies by quantitative RT-PCR demonstrated that the PPK gene is transcribed not only in the liver, but also at significant levels in non-hepatic human tissues (Figure 1, from Neth et al., 2001). Here we examined the question as to whether PPK mRNA in extrahepatic tissues is actually translated into the zymogen protein. We used an immunohistochemical approach to immunolabel PPK/PK in different embryologically derived human tissues primarily of metanephric/mesenchyme, ectodermal/ endodermal and endocrine/neural crest lineage, and localised PPK/PK to cells of all tissues investigated. The cellular delineation of PPK/PK in different progenitor derived cells indicates specific cellular functions of plasma kallikrein, in addition to its known function in the blood.

\section{Results}

\section{Cross-reactivity of PPK/PK antibodies with human IgG}

During the validation of an antibody to human PPK for use in immunohistochemical studies, we noted strong cross-reactivity with human IgG (cf. materials and methods). The reason for this cross-reactivity is obviously due to the fact that, depending on the isolation procedure, preparations of human PPK may contain IgG as a minor contaminant (Gallimore et al., 1978). Since IgG acts as an excellent antigen, even spurious amounts of lgG, such as present in commercially available PPK, will give rise to the generation of antibodies. To prevent cross-reactivity with IgG in our immunohistochemical studies, we removed antibodies to IgG by affinity chromatography on IgG-Sepharose. In two recent publications [arising from a project proposal by EF and KDB on PK/PPK (Volks- 


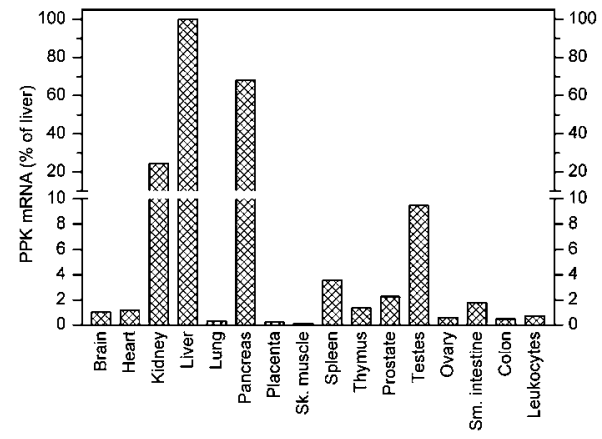

Figure 1 Expression of plasma prekallikrein mRNA in human tissues.

The expression of PPK mRNA in non-hepatic tissues is shown as a percentage of expression in liver (Figure modified and reproduced with permission from Neth et al., 2001).

wagen Foundation Grant) with a collaborating group] on the immunolocalisation of PPK/PK in human blood vessels (Cerf et al., 1999) and in human brain (Cerf and Raidoo, 2000), the antibodies used had been raised against commercially available PPK and had not been validated with respect to cross-reactivity with human IgG; therefore, these data have to be interpreted with caution.

We also observed cross-reactivity with IgG for the PKspecific antibody (U691.10) raised against a peptide antigen, but in this case the IgG cross-reactivity (approx. one-fifth compared to $\mathrm{PK}$ ) was obviously due to sequence similarity of the peptide antigen with sequence motifs of IgG heavy chains (cf. materials and methods).

To investigate whether any of the antibodies used for PK/PPK localisation also detected IgG in human tissue, we compared their immunoreactivity to PPK/PK with that to a commercial antibody to human IgG on human kidney sections. While antibodies to PPK/PK showed clear cellular localisation in various portions of human nephron, the antibody to human $\lg G$ detected immunoreactivity only in the renal interstitium and lumen of blood vessels, including glomerular capillaries (not shown).

\section{Plasma kallikrein-specific antibody}

With the aim of discriminating PK and PPK in tissue sections, an antibody was raised against a peptide that represents the C-terminal end of the heavy chain of PK, which is newly formed upon activation of PPK by cleavage of the $\mathrm{Arg}^{371}-\mathrm{Il}^{372}$ peptide bond. Therefore, antibodies against this peptide should be specific for active PK. Western blot experiments revealed that the sensitivity of antibody U691.10 for PK is at least ten-fold higher than for PPK, since $0.3 \mu \mathrm{g}$ of PK gave a very intense signal, whereas $2 \mu \mathrm{g}$ of PPK resulted in a barely visible band (data not shown). However, positive staining obtained with this antibody in immunolocalisation studies was identical to that for the other four antibodies that detect both PK and PPK. Therefore, we assume that the PK detected by this PK-specific antibody is due to activation of PPK during tissue processing.

\section{Visualisation of immunolabelled human PPK/PK in human tissues}

Kidney Kidney exhibited the third highest PPK mRNA expression (24.5\% compared to liver; Neth et al., 2001) and therefore significant positive immunostaining for PK/ PPK was expected. In the current study we observed intense staining of PPK/PK in cells of the proximal tubules (Figure 2C,D), distal tubules and collecting ducts (Figure 2E). Staining was also observed in epithelial cells of Bowman's capsule (Figure 2B). All of these cells were uniformly stained, whereas in distal tubules a similar intensity of immunolabelling was visualised only in single cells identified as connecting tubule cells after performing double staining techniques (PPK/PK and tissue kallikrein, hK1; data not shown). Cellular visualisation of PPK/PK with the five antibodies (see methods) was essentially similar. Interestingly, immunoreactivity was occasionally observed in nuclei and the nuclear envelope of some tubular cells (Figure 2D). Controls in which the anti-PPK/PK antiserum was replaced by non-immune serum or preabsorbed with excess antigen showed no immunostaining (Figure 2F).

Liver Although hepatocytes were considered to synthesise plasma prekallikrein and PPK mRNA expression was highest in the liver (Neth et al., 2001), direct evidence of its presence in the liver was obtained only when the enzyme was demonstrated in isolated hepatocytes by immunofluorescence (Henderson et al., 1992). In the current study, we confirmed the localisation of PPK/PK in human hepatocytes (Figure 3A). It is therefore assumed that following synthesis, PPK is secreted together with $\mathrm{H}$-kininogen into the liver sinusoids. Immunostaining was intense in some cells, while others were faintly stained (Figure 3A).

Oesophagus and skin Staining was concentrated in the squamous epithelium of oesophagus and epidermis (Figure 3B,F). Again the immunoreactive protein was intensely expressed in the nuclei of numerous epithelial cells forming the squamous epithelium of the oesophagus and epidermis.

Parotid gland Immunoreactive PPK/PK was observed in acinar cells of the parotid gland. Staining was more intense on the apical cell membrane of acinar cells, suggesting a cell membrane distribution of the enzyme (Figure 3E).

Stomach In the stomach, PPK/PK staining appeared to be confined to the parietal cells of the gastric mucosa, whose major function is the secretion of hydrochloric acid (data not shown).

Respiratory tract With $0.3 \%$ compared to liver, mRNA expression in lung was very low (Neth et al., 2001). Nevertheless, as in the epithelium of other glandular organs, epithelial cells forming the respiratory epithelium stained positively for PPK/PK. The respiratory epithelium stained with similar intensity at different levels of the respiratory tree, namely trachea, bronchi and bronchioles (Figure 3C,D). Staining of nuclei of epithelial cells was also observed with variable strength. Goblet cells did not appear to express immunoreactive PPK/PK.

Prostate and breast These glandular organs expressed immunoreactivity for PPK/PK in epithelial cells 

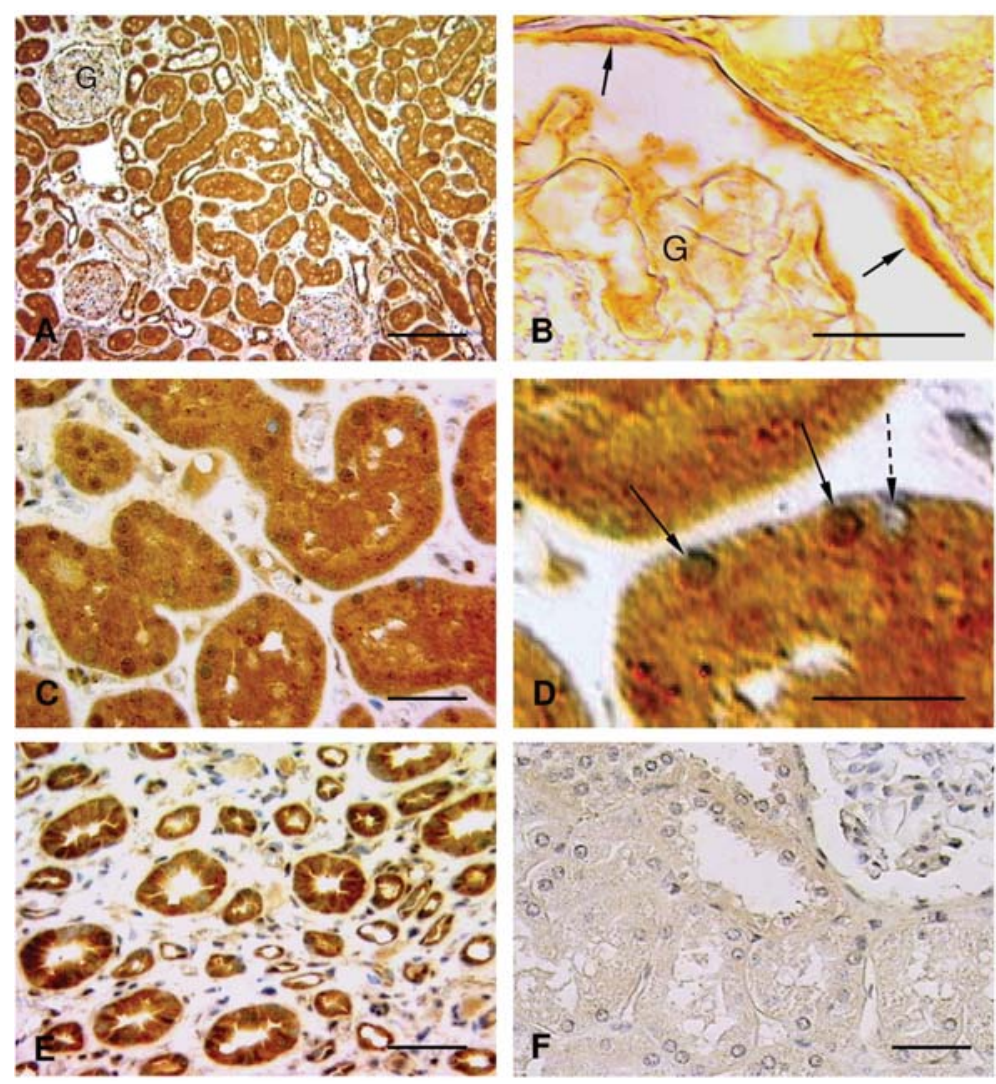

Figure 2 Immunolocalisation of PPK/PK in human kidney.

Immunoreactivity is associated with tubular segments of the human nephron (A), including proximal tubules (C, D) and medullary collecting ducts (E). Immunostaining is also observed in epithelial (parietal) cells (arrows) of Bowman's capsule (B) and in some nuclei of proximal tubule cells ( $\mathrm{D}$, solid arrows) while others remain unstained ( $\mathrm{D}$, broken arrow). Replacement of anti-PPK/PK antibody by non-immune serum resulted in the absence of staining (F). G, glomerulus. Scale bars: (A,E) $200 \mu \mathrm{m} ;(B, D) 25 \mu \mathrm{m} ;(C, F) 50 \mu \mathrm{m}$.

forming both ducts and acini, but the staining intensity was stronger in ducts than in the acini of human breast (Figure 3G,H).

Pancreas We visualised intense specific staining for PPK/PK in endocrine cells forming the islets of Langerhans. The exocrine portion of the gland did not express significant immunoreactivity compared to the endocrine portion (Figure 4A,B). In accordance with the pattern of staining observed in the islets, it seems highly likely that immunoreactive PPK/PK is expressed in insulin-secreting cells. PPK mRNA expression in pancreas (Neth et al., 2001 ) was $68 \%$ of that in liver, which may indicate a high level of transcription in the islets of Langerhans, since the islets represent only $\sim 1-2 \%$ of the mass of pancreatic tissue.

Ovary In the ovary, follicular granulosa cells showed immunostaining for PPK/PK (Figure 4C,D), which begins to disappear in the atresic follicles after luteinisation. Our previous analyses showed that PPK mRNA expression in ovary was low, at approximately $0.6 \%$ of the value for liver (Neth et al., 2001).

Testes Intense staining for PPK/PK was visualised in Leydig cells (Figure 4E,F). Other components of the organ, such as the seminiferous tubules, were free of detectable staining (Figure 4E). Relative to the expression of PPK mRNA in liver, the value for testes was approxi- mately $10 \%$ (Neth et al., 2001). Immunoreactivity of the nuclear envelope of Leydig cells was also a characteristic observation (Figure 4F).

\section{Discussion}

Early experiments focused on a critical analysis of the molecular steps that control the participation of PPK in contact activation, regulatory control of vascular tone, fibrinolysis and initiation of the inflammation cascade. Subsequent in vitro studies examined the contact activation events that lead to the conversion of PPK to active PK. This molecular step was achieved by cleavage of the peptide bond $\operatorname{Arg}^{371}-I^{372}$, either in the fluid phase by factor XII fragment (bFXIla) or on a negatively charged surface by activated factor XII (FXIla) with high-molecular-weight kininogen as cofactor (contact activation). FXIla-independent PPK activation has been shown to take place on the surface of endothelial cells: PPK, assembled on endothelial cell surface-bound highmolecular-weight kininogen as a multiprotein complex that comprises cytokeratin 1, gClqR and plasminogen activator receptor, is activated in the absence of FXIla by a protease (Colman and Schmaier, 1997; Motta et al., $1998,2001)$ which has been identified as prolylcarboxypeptidase (Shariat-Madar et al., 2002). In addition, it has been evidenced that activation of prekallikrein complexed to kininogen on the endothelial cell surface 

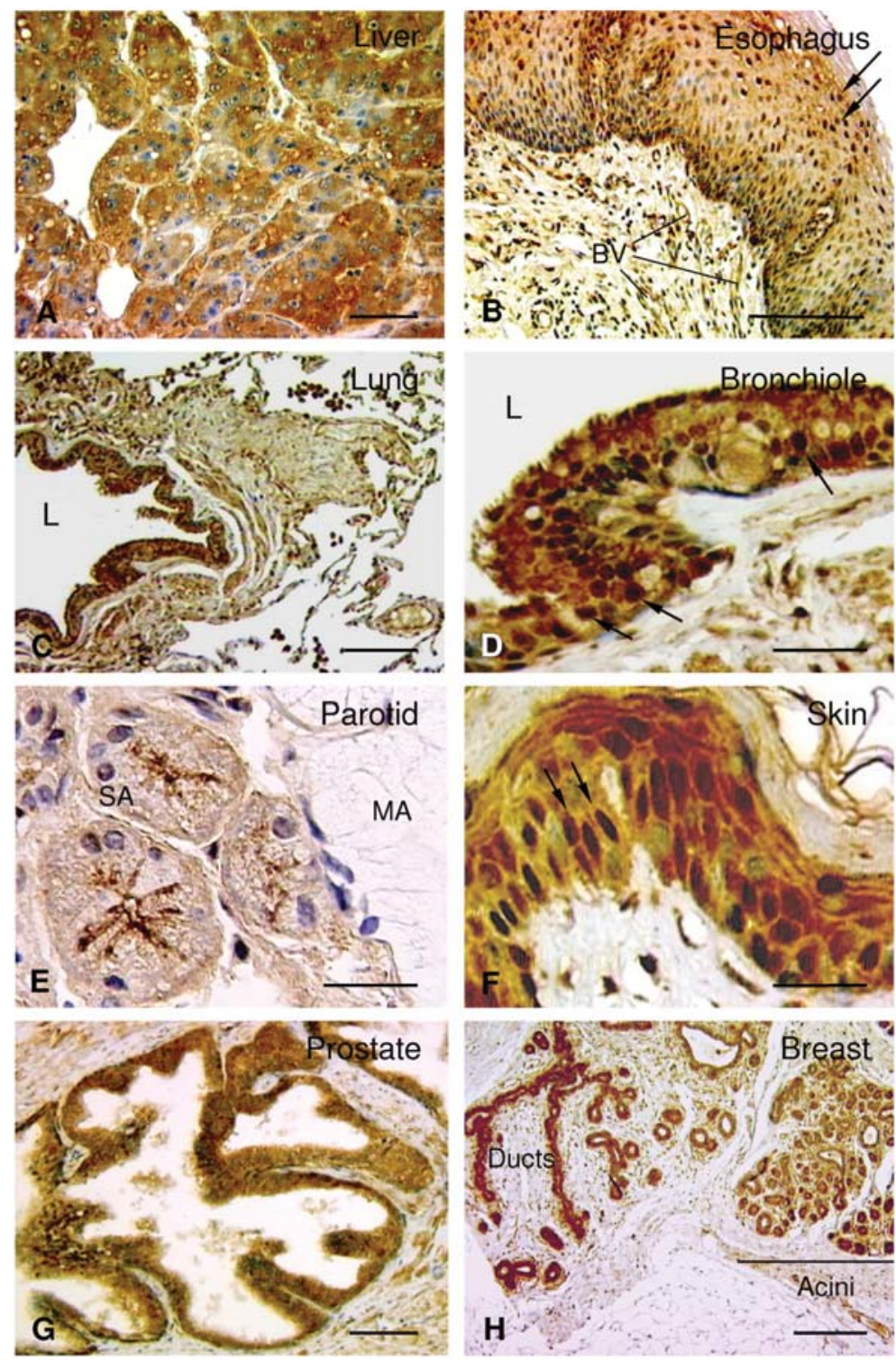

Figure 3 Immunoperoxidase labelling of PPK/PK in human liver (A), oesophagus (B), lung (C, D), parotid gland (E), skin (F), prostate $(\mathrm{G})$ and breast $(\mathrm{H})$.

Arrows indicate nuclear localisation of the enzyme in epithelial cells of oesophagus (B), respiratory tract (D) and epidermis (F). BV, blood vessels; L, lumen; SA, serous acinus; MA, mucous acinus. Scale bars: (A,G) $40 \mu \mathrm{m} ;(\mathrm{C}, \mathrm{H}) 200 \mu \mathrm{m}$; (E) $30 \mu \mathrm{m}$; (B,D,F) $50 \mu \mathrm{m}$.

can be catalysed by heat shock protein 90 by an as yet unidentified mechanism (Joseph et al., 2002).

The protease activity of PK is also involved in the activation of circulating neutrophils (Schapira et al., 1982, 1983; Wachtfogel et al., 1983); it efficiently converts prourokinase plasminogen activator, thereby inducing the fibrinolytic cascade (Ichinose et al., 1986; Hauert et al., 1989). A major function of PK is the release from highmolecular-weight kininogen of the nonapeptide bradykinin, which through its specific receptor-coupling of second messengers regulates cellular events (Bhoola et al., 1992; Blais et al., 2000). Whether or not PPK, together with FXII and high-molecular-weight kininogen, contributes to haemostasis is at present questionable (Colman and Schmaier, 1997; Schmaier, 1998).

For some time the synthesis and cellular localisation of PPK was regarded as residing exclusively in the hepatocyte, which secretes the pre-protease PPK and its co-factor high-molecular-weight kininogen into the circulation. The molecules circulate as a complex either free or attached to the external surface of neutrophils (Schapira et al., 1982; Henderson et al., 1994). Experimental evidence gathered from RT-PCR studies clearly suggested PPK mRNA expression in several extra-hepatic tissues (Ciechanowicz et al., 1993; Hermann et al., 1996, 1999). Recently we confirmed and extended these studies and demonstrated by quantitative RT-PCR the expression of PPK mRNA in 16 human tissues (Figure 1, Neth et al., 2001). Therefore, it was expected that the PPK protein is synthesised in various tissues. However, studies on the localisation of the protein are scarce. Besides Cerf et al. (1999) and Cerf and Raidoo (2000) (cf. the results section), Hermann et al. (1996) localised PPK/ $\mathrm{PK}$ on the endothelial cells of villous capillaries of human term placenta, but the authors suggested that endothelial cells may adsorb the protein from foetal blood. Thus, 

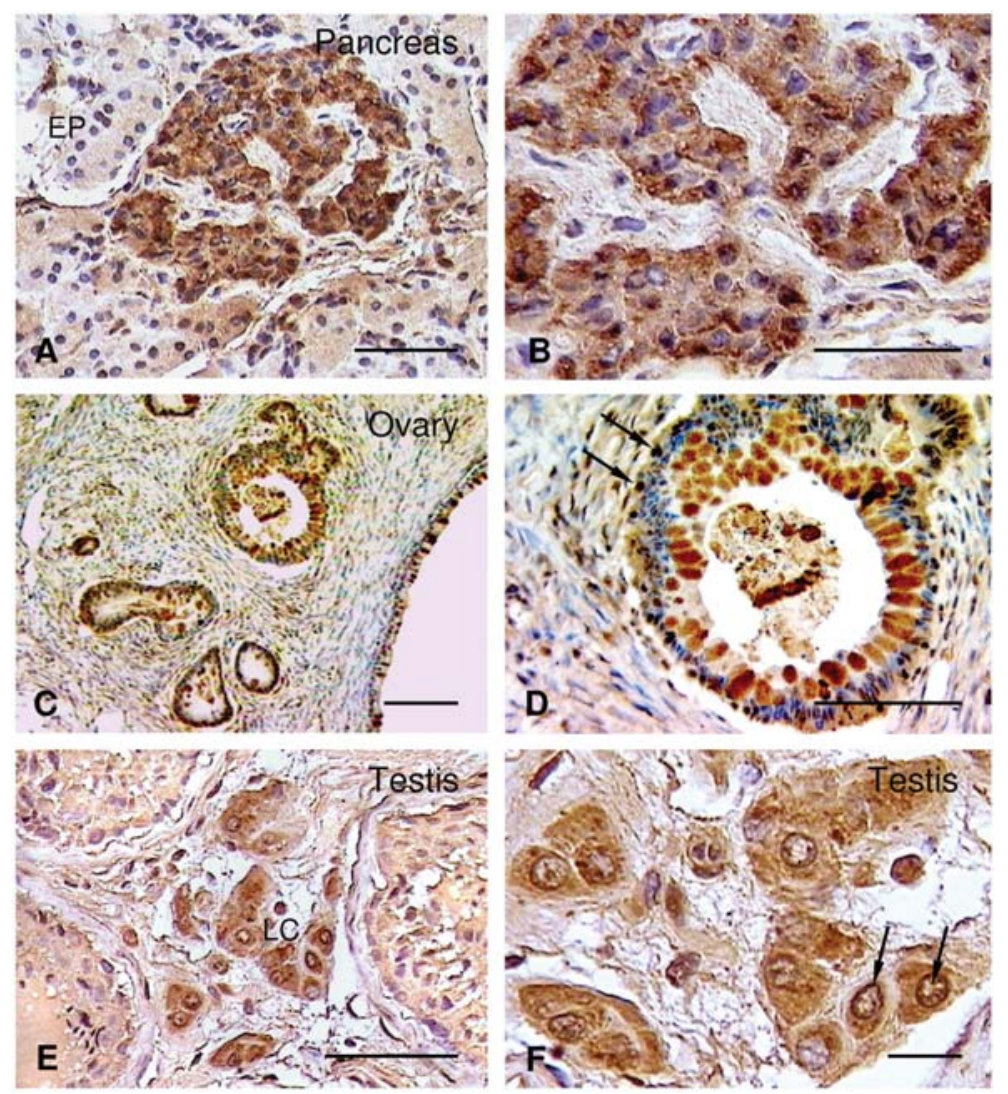

Figure 4 Immunoreactive PPK/PK expression in endocrine cells of Langerhans islets of human pancreas (A, B), follicular granulosa cells $(C, D)$, and Leydig cells $(E, F)$.

Arrows indicate nuclear localisation of the enzyme in follicular granulosa cells (D) and in Leydig cells (F). LC, Leydig cells. Scale bars: $(A, D, E) 100 \mu \mathrm{m}$; (C) $200 \mu \mathrm{m}$; (B,F) $50 \mu \mathrm{m}$.

whereas PPK gene transcription in non-hepatic tissues is now well documented, the question addressed here was whether PPK mRNA could evoke expression of the zymogen protein. In essence and most importantly, a wide variety of progenitor-derived cells showed the capacity to synthesise the enzyme, as evidenced from our immunolabelling experiments. Although no quantitative comparison of PPK mRNA expression and PPK/PK protein content in the tissues is possible from the present study, it is interesting to note that significant immunoreactivity to PPK/PK was detected in tissues expressing very low levels of PPK mRNA, such as lung and ovary.

The possibility that the immunolocalised PK/PPK represents enzyme non-specifically adsorbed from the blood plasma can be ruled out, since in that case labelling of all cells of a tissue and not only of defined cell types would be expected. A second possibility, namely that PPK is - despite the cellular expression of its mRNA - not synthesised, but selectively internalised by defined cells, is improbable.

The next question to address is the physiological importance of the almost universal occurrence of the enzyme in the cytoplasm and on the nuclear envelope of immunoreactive cells. It is reasonable to assume that the PPK synthesised in these cells may subserve special local functions at or near the cellular site of its synthesis. Recently, a novel function of PK was described that provides experimental evidence of direct activation of the kinin $B_{2}$ receptor, independent of kinin release (Hecquet et al., 2000, 2002; Biyashev et al., 2006). The proteolytic activity of $\mathrm{PK}$ is compulsory for this receptor activation, but the mechanism of action seems to be different from that of the known proteinase-activated receptors (Dery et al., 1998). Unlike tissue kallikrein hK1, PPK appears to be mainly expressed as a non-granular protein, suggestive of an intracrine function. On the other hand, it may be postulated that the proteolytic regulation of adipogenesis (Selvarajan et al., 2001), the activation of pro-hepatocyte growth factor (Peek et al., 2002) and the latent form of transforming growth factor (Akita et al., 2002) are functions of PPK/PK that resides in the endoplasmic reticulum of particular cells. The novel finding of PPK/PK on the nuclear membrane provides new evidence of the participation of PK in regulating mechanisms at this site. In our study we demonstrated that PPK/PK is indeed detectable in cells of a variety of embryologically derived cells, giving credence to the concept that PK may modulate specialised cytoplasmic and nuclear functions of many human cells.

\section{Materials and methods}

\section{Ethical permission}

Ethical permission for the study was obtained from the Ethics Committee of the University of Natal Medical School, Durban, South Africa. 


\section{Tissue collection and processing}

Surgical and autopsy samples were collected from different embryologically derived human tissues: (1) metanephric blastema-derived renal tissue; (2) endodermal/ectodermal tissues including liver, parotid glands, lung and bronchi, oesophagus, breast, prostate and skin; and (3) endocrine tissue consisting of pancreas, ovary and testes. Post-mortem samples were collected within $24 \mathrm{~h}$ of death and were obtained from individual corpses who had been immediately refrigerated and maintained at $4^{\circ} \mathrm{C}$. The specimens were fixed in $5 \%$ formalin saline for $24 \mathrm{~h}$ at room temperature and paraffin-embedded using conventional procedures. In addition, arrays of adult human tissues were purchased from BioCat (Heidelberg, Germany). These slides were pre-treated according to the manufacturer's instructions.

\section{Antibodies}

To optimise the antibody dilution for immunohistochemistry, as a first step all antibodies were diluted within the range 1:50 to 1:300. In this study five different antibody preparations were used. (i) A polyclonal antiserum AS176 against human PPK was raised in New Zealand white rabbits. The lyophilised whole antiserum was reconstituted in deionised water and used at a dilution of 1:400 in phosphate-buffered saline (PBS). (ii) Murine monoclonal antibodies PK7 and PK11 are directed against the human PPK heavy and light chains, respectively. Lyophilised ascites fluid was reconstituted in deionised water and used at dilutions of $1: 150$ and 1:450, respectively, in PBS. The preparation and characterisation of these antibodies has been described previously (Hock et al., 1990; Herwald et al., 1993). These three antibodies were generous gifts of Prof. W. MüllerEsterl, Johann Wolfgang Goethe-University, Frankfurt, Germany. (iii) A rabbit antiserum to human PPK was kindly provided by Prof. B.N. Bouma, Utrecht University, The Netherlands. The IgG was isolated by affinity chromatography on Protein G-Sepharose (Pharmacia, Uppsala, Sweden). Since immunoblotting showed that the preparation contained antibodies against human IgG, the antibody was additionally passed through a human IgGSepharose column. Fractions of the flow-through containing lgG not adsorbed onto the column (PK427.10) were collected and lyophilised. Western blot experiments with PK427.10 demonstrated that the antibodies reacting with human IgG had been removed successfully, since the signal obtained with $0.2 \mu \mathrm{g}$ of PK or PPK was stronger than that of $375 \mathrm{nl}$ of human plasma (approx. $6 \mu \mathrm{g}$ of $\mathrm{lgG}$ ). Furthermore, immunoreactivity of this and the other antibodies was compared on human kidney sections with that observed using an anti-human $\lg G$ antibody purchased from Dako (Carpinteria, CA, USA). This antibody was used at a dilution of 1:50 in PBS. (iv) Antiserum U691.10 to the peptide CTTKTSTR, representing the C-terminal end of the PK heavy chain, was raised in rabbits by a commercial service (Eurogentec, Liège, Belgium). The IgG was isolated from the antiserum by affinity chromatography on a Protein A-Sepharose column. The IgG-containing fractions were pooled and lyophilised. The antibody preparation was used at a dilution of 1:50. U691.10 should be specific for active PK. Unexpectedly, in Western blot experiments antibody U691.10 also detected human IgG. This cross-reactivity with human IgG is presumably caused by a sequence similarity, since a BLAST search found five sequences of human IgG heavy chains with sequence motifs with $50 \%$ or $63 \%$ identity with the peptide used for immunisation [CTxxTS, TTxTST, TTxxSTR $(n=2)$ and CTTxxST]. In fact, in a Western blot experiment with reduced human $\lg G$ a weak single band of $50 \mathrm{kDa}$ was detected, obviously representing the heavy chain of lgG.

All five antibodies were equally well suited for detecting PPK/ PK in human tissue sections.

\section{Immunohistochemistry}

Paraffin-embedded sections were dewaxed with xylene and rehydrated through a graded series of ethanol and finally in distilled water. Antigen retrieval was performed by boiling the slides in $0.1 \mathrm{M}$ sodium citrate, $\mathrm{pH} 6.0$ in a microwave oven (Sharp R4A52, Mahway, NJ, USA) at high power for 3 min, at low power for $5 \mathrm{~min}$ and finally allowing them to cool at room temperature for $20 \mathrm{~min}$. Endogenous pseudoperoxidase activity was inactivated by incubating the sections with $5 \% \mathrm{H}_{2} \mathrm{O}_{2}$ in absolute methanol for $30 \mathrm{~min}$. Non-specific binding sites were masked by incubating the sections with non-immune serum for $30 \mathrm{~min}$ at room temperature. The sections were then probed for the presence of immunoreactive PPK/PK with the antibodies mentioned above. After overnight incubation with the primary antibody at $4^{\circ} \mathrm{C}$, the sections were thoroughly washed and incubated with the biotinylated secondary anti-species antibody, followed by the streptavidin-peroxidase complex (Dako). The enzyme-substrate reaction was detected using diaminobenzidine. After immunostaining, tissue sections were lightly counterstained with Harris haematoxylin, dehydrated and mounted in DPX, and visualised using a Nikon light microscope. To assess the specificity of the immunolabelling method, controls were prepared in which the primary antibody solution was replaced by PBS, non-immune serum, or a solution of the primary antibody preabsorbed by PPK.

\section{Acknowledgements}

This work was generously supported by grant 73472 from the Volkswagen Foundation, Germany. We are particularly grateful to the Medical Research Council and the National Research Foundation, South Africa for research grant support. We are very grateful to Prof. B.N. Bouma, Utrecht, for providing anti-PPK serum and Professor Werner Müller-Esterl for the monoclonal and polyclonal PPK antibodies. K.D.B. wishes to thank Lung Institute of Western Australia for financial support.

\section{References}

Akita, K., Okuno, M., Enya, M., Imai, S., Moriwaki, H., Kawada, N., Suzuki, Y., and Kojima, S. (2002). Impaired liver regeneration in mice by lipopolysaccharide via TNF- $\alpha$ /kallikreinmediated activation of latent TGF- $\beta$. Gastroenterology 12 , 35-36.

Asakai, R., Davie, E.W., and Chung, D.W. (1987). Organization of the gene for human factor XI. Biochemistry 26, 7221-7228.

Bhoola, K.D., Figueroa, C.D., and Worthy, K. (1992). Bioregulation of kinins: kallikreins, kininogens, and kininases. Pharmacol. Rev. 44, 1-80.

Biyashev, D., Tan, F.L., Chen, Z.L., Zhang, K., Deddish, P.A., Erdos, E.G., and Hecquet, C. (2006). Kallikrein activates bradykinin B-2 receptors in absence of kininogen. Am. J. Physiol. Heart Circ. Physiol. 290, H1244-H1250.

Blais, C., Marceau, F., Rouleau, J.L., and Adam, A. (2000). The kallikrein-kininogen-kinin system: lessons from the quantification of endogenous kinins. Peptides 21, 1903-1940.

Cerf, M.E. and Raidoo, D.M. (2000). Immunolocalization of plasma kallikrein in human brain. Metab. Brain. Dis. 15, 315-323.

Cerf, M., Raidoo, D., Fink, E., Fritz, H., and Bhoola, K.D. (1999). Plasma kallikrein localisation in human blood vessels. Immunopharmacology 44, 75-80.

Ciechanowicz, A., Bader, M., Wagner, J., and Ganten, D. (1993). Extra-hepatic transcription of plasma prekallikrein gene in human and rat tissue. Biochem. Biophys. Res. Commun. 197, 1370-1376. 
Colman, R.W. and Schmaier, A.H. (1997). Contact system: a vascular biology modulator with anticoagulant, profibrinolytic, antiadhesive, and proinflammatory attributes. Blood 90, 3819-3843.

Dery, O., Corvera, C.U., Steinhoff, M., and Bunnett, N.W. (1998). Proteinase-activated receptors: novel mechanisms of signaling by serine proteases. Am. J. Physiol. 274, C1429-C1452.

Gallimore, M.J., Fareid, E., and Stormorken, H. (1978). The purification of a human plasma kallikrein with weak plasminogen activator activity. Thromb. Res. 12, 409-420.

Hauert, J., Nicoloso, G., Schleuning, W.D., Bachmann, F., and Schapira, M. (1989). Plasminogen activators in dextran sulfate-activated euglobulin fractions: a molecular analysis of factor XII- and prekallikrein-dependent fibrinolysis. Blood 73, 994-999.

Hecquet, C., Tan, F.L., Marcic, B.M., and Erdös, E.G. (2000). Human bradykinin $B_{2}$ receptor is activated by kallikrein and other serine proteases. Mol. Pharmacol. 58, 828-836.

Hecquet, C., Becker, R.P., Tan, F., and Erdos, E.G. (2002). Kallikreins when activating bradykinin $B_{2}$ receptor induce its redistribution on plasma membrane. Int. Immunopharmacol. 2, 1795-1806.

Henderson, L., Figueroa, C.D., Müller-Esterl, W., Strain, A., and Bhoola, K.D. (1992). Immunovisualisation of plasma prekallikrein and $\mathrm{H}$-kininogen on human neutrophils and in human hepatocytes. Agents Actions 38 (Suppl.), 590-594.

Henderson, L.M., Figueroa, C.D., Müller-Esterl, W., and Bhoola, K.D. (1994). Assembly of contact phase factors on the surface of the human neutrophil membrane. Blood 84, 474-482.

Hermann, A., Buchinger, P., Somlev, B., and Rehbock, J. (1996). High and low molecular weight kininogen and plasma prekallikrein/plasma kallikrein in villous capillaries of human term placenta. Placenta 17, 223-230.

Hermann, A., Arnhold, M., Kresse, H., Neth, P., and Fink, E. (1999). Expression of plasma prekallikrein mRNA in human nonhepatic tissues and cell lines suggests special local functions of the enzymes. Biol. Chem. 380, 1097-1102.

Herwald, H., Jahnen-Dechent, W., AbdAlla, S.A., Hock, J., Bouma, B.N., and Müller-Esterl, W. (1993). Mapping of the high molecular weight kininogen binding site of prekallikrein. J. Biol. Chem. 268, 1-9.

Hock, J., Vogel, R., Linke, R.P., and Müller-Esterl, W. (1990). High molecular weight kininogen-binding site of prekallikrein probed by monoclonal antibodies. J. Biol. Chem. 265, 12005-12011.
Ichinose, A., Fujikawa, K., and Suyama, T. (1986). The activation of pro-urokinase by plasma kallikrein and its inactivation by thrombin. J. Biol. Chem. 261, 3486-3489.

Joseph, K., Tholanikunnel, B.G., and Kaplan, A.P. (2002). Heat shock protein 90 catalyzes activation of the prekallikrein-kininogen complex in the absence of factor XII. Proc. Natl. Acad. Sci. USA 99, 896-900.

Motta, G., Rojkjaer, R., Hasan, A.A., Cines, D.B., and Schmaier, A.H. (1998). High molecular weight kininogen regulates prekallikrein assembly and activation on endothelial cells: a novel mechanism for contact activation. Blood 91, 516-528.

Motta, G., Shariat-Madar, Z., Mahdi, F., Sampaio, C.A.M., and Schmaier, A.H. (2001). Assembly of high molecular weight kininogen and activation of prekallikrein on cell matrix. Thromb. Haemost. 86, 840-847.

Neth, P., Arnhold, M., Nitschko, H., and Fink, E. (2001). The mRNAs of prekallikrein, factors XI and XII, and kininogen, components of the contact phase cascade are differentially expressed in multiple non-hepatic tissues. Thromb. Haemost. 85, 1043-1047.

Peek, M., Moran, P., Mendoza, N., Wickramasinghe, D., and Kirchhofer, D. (2002). Unusual proteolytic activation of prohepatocyte growth factor by plasma kallikrein and coagulation factor Xla. J. Biol. Chem. 277, 47804-47809.

Schapira, M., Despland, E., Scott, C.F., Boxer, L.A., and Colman, R.W. (1982). Purified human plasma kallikrein aggregates human blood neutrophils. J. Clin. Invest. 69, 1199-1202.

Schapira, M., Scott, C.F., Boxer, L.A., and Colman, R.W. (1983). Activation of human polymorphonuclear leukocytes by purified human plasma kallikrein. Adv. Exp. Med. Biol. 156, 747753.

Schmaier, A.H. (1998). Plasma contact activation: a revised hypothesis. Biol. Res. 31, 251-262.

Selvarajan, S., Lund, L.R., Takeuchi, T., Craik, C.S., and Werb, Z. (2001). A plasma kallikrein-dependent plasminogen cascade required for adipocyte differentiation. Nat. Cell Biol. 3, 267-275.

Shariat-Madar, Z., Mahdi, F., and Schmaier, A.H. (2002). Identification and characterization of prolylcarboxypeptidase as an endothelial cell prekallikrein activator. J. Biol. Chem. 277, 17962-17969.

Wachtfogel, Y.T., Kucich, U., James, H.L., Scott, C.F., Schapira, M., Zimmerman, M., Cohen, A.B., and Colman, R.W. (1983). Human plasma kallikrein releases neutrophil elastase during blood coagulation. J. Clin. Invest. 72, 1672-1677.

Received December 28, 2006; accepted May 23, 2007 